\title{
Prevalence of Self-Reported Hypertension and Antihypertensive Medication Use Among Adults Aged $\geq 18$ Years — United States, 2011-2015
}

\author{
Jing Fang, $\mathrm{MD}^{1}$; Cathleen Gillespie, $\mathrm{MS}^{1}$; Carma Ayala, $\mathrm{PhD}^{1}$; Fleetwood Loustalot, $\mathrm{PhD}^{1}$
}

Hypertension, which affects nearly one third of adults in the United States, is a major risk factor for heart disease and stroke (1), and only approximately half of those with hypertension have their hypertension under control (2). The prevalence of hypertension is highest among non-Hispanic blacks, whereas the prevalence of antihypertensive medication use is lowest among Hispanics (1). Geographic variations have also been identified: a recent report indicated that the Southern region of the United States had the highest prevalence of hypertension as well as the highest prevalence of medication use (3). Using data from the Behavioral Risk Factor Surveillance System (BRFSS), this study found minimal change in state-level prevalence of hypertension awareness and treatment among U.S. adults during the first half of the current decade. From 2011 to 2015, the age-standardized prevalence of self-reported hypertension decreased slightly, from $30.1 \%$ to $29.8 \%$ ( $\mathrm{p}=0.031$ ); among those with hypertension, the age-standardized prevalence of medication use also decreased slightly, from $63.0 \%$ to $61.8 \%$ $(\mathrm{p}<0.001)$. Persistent differences were observed by age, sex, race/ethnicity, level of education, and state of residence. Increasing hypertension awareness, as well as increasing hypertension control through lifestyle changes and consistent antihypertensive medication use, requires diverse clinical and public health intervention.

BRFSS is a state-based telephone survey of noninstitutionalized adults aged $\geq 18$ years. ${ }^{*}$ Data for this study were taken from the fixed core questions asked every year and the rotating core questions asked every other year. Hypertension awareness questions, included in the rotating core, were asked in odd years. New survey methods were introduced to the BRFSS in 2011; thus, available data from 2011 to 2015 were used for trend analyses. The median state-specific response rates in 2011, 2013 , and 2015 were $49.7 \%$ (range $=33.8 \%-64.1 \%$ ), $45.9 \%$ (29.0\%-59.2\%), and 47.2\% (33.9\%-61.1\%), respectively. ${ }^{\dagger}$

Self-reported diagnosed hypertension was ascertained by an affirmative response to the question "Have you ever been told by a doctor, nurse, or other health professional that you have high blood pressure?" To determine whether persons with hypertension were being treated, respondents who answered "yes" were asked "Are you currently taking medicine

\footnotetext{
*https://www.cdc.gov/brfss.

$\dagger$ According to the guidelines for the American Association of Public Opinion Research.
}

for your high blood pressure?" Hypertension and treatment were assessed by age group (18-44 years, 45-64 years, and $\geq 65$ years), sex, race/ethnicity (non-Hispanic whites [whites]; non-Hispanic blacks [blacks]; Hispanics; non-Hispanic Asians [Asians]; non-Hispanic Native Hawaiian/Pacific Islanders [NH/PIs]; non-Hispanic American Indian/Alaskan Natives [AI/ANs]); and non-Hispanic others [others]), highest level of education attained (less than high school graduate, high school graduate, some college, college graduate or higher), and state of residence. Estimates were directly age-standardized to the 2000 U.S. standard population. Changes over time were assessed using t-tests for the differences from 2011 to 2015 . Because of a large difference in the age distribution between persons with hypertension and the general population, both age-standardized and crude estimates were calculated. All analyses were conducted using statistical software to account for the complex sampling design.

Overall, 497,967, 483,865, and 434,382 participants were interviewed in 2011, 2013, and 2015, respectively. After excluding participants who were pregnant $(0.5 \%-0.6 \%)$, missing data for hypertension variables $(0.3 \%-0.4 \%)$ and other covariates $(2.0 \%-2.8 \%)$, the final analytic samples for 2011, 2013 and 2015 were 483,120 (97\% of original sample), 465,739 (96\%), and 418,317 (96\%), respectively. From 2011 to 2015, the overall age-standardized prevalence of self-reported hypertension decreased from $30.1 \%$ to $29.8 \%$ $(\mathrm{p}=0.031)$. Hypertension prevalence was higher in 2015 among adults aged $\geq 65$ years $(61.7 \%)$, men $(32.5 \%)$, blacks $(40.3 \%)$, and persons with less than high school education (35.1\%) compared with younger adults, women (27.1\%), Asians (24.6\%), and persons with higher levels of education (Table 1). Statistically significant, but minimal, declines in the prevalence of hypertension from 2011 to 2015 were observed among women $(28.1 \%$ to $27.1 \%)$, persons aged $\geq 65$ years $(62.2 \%$ to $61.7 \%)$, and persons with some college education (30.5\% to $29.8 \%$ ). In contrast, an increase in hypertension prevalence was observed among persons with less than high school education $(34.1 \%$ to $35.1 \%)$.

By state, the age-standardized prevalence of self-reported hypertension ranged from $24.2 \%$ in Minnesota to $40.1 \%$ in Mississippi in 2015 (Table 1). From 2011 to 2015, significant increases in the prevalence of hypertension were observed in five states (Arkansas, Georgia, Hawaii, North Carolina, and West Virginia) 
Morbidity and Mortality Weekly Report

TABLE 1. Age-standardized prevalence of self-reported hypertension among adults aged $\geq 18$ years by sociodemographic characteristics and state* - Behavioral Risk Factor Surveillance System, United States 2011-2015

\begin{tabular}{|c|c|c|c|c|c|}
\hline \multirow[b]{2}{*}{ Characteristic } & \multicolumn{3}{|c|}{$\%(95 \% \mathrm{Cl})$} & \multicolumn{2}{|c|}{ Change 2011-2015 } \\
\hline & 2011 & 2013 & 2015 & $\%$ & p-value ${ }^{\dagger}$ \\
\hline Total & $30.1(29.9-30.4)$ & $30.6(30.3-30.8)$ & $29.8(29.5-30.0)$ & -0.3 & 0.031 \\
\hline $\begin{array}{l}\text { Sex } \\
\text { Male } \\
\text { Female }\end{array}$ & $\begin{array}{l}32.1(31.7-32.4) \\
28.1(27.8-28.4)\end{array}$ & $\begin{array}{l}32.8(32.4-33.2) \\
28.3(28.0-28.6)\end{array}$ & $\begin{array}{l}32.5(32.1-32.9) \\
27.1(26.8-27.4)\end{array}$ & $\begin{array}{r}0.4 \\
-1.0\end{array}$ & $\begin{array}{r}0.096 \\
<0.001\end{array}$ \\
\hline $\begin{array}{l}\text { Age group (yrs) } \\
18-44 \\
45-64 \\
\geq 65\end{array}$ & $\begin{array}{l}14.1(13.8-14.5) \\
40.2(39.8-40.6) \\
62.2(61.7-62.7)\end{array}$ & $\begin{array}{l}14.2(13.8-14.5) \\
41.1(40.7-41.6) \\
63.0(62.5-63.5)\end{array}$ & $\begin{array}{l}13.7(13.4-14.1) \\
40.2(39.7-40.6) \\
61.7(61.1-62.2)\end{array}$ & $\begin{array}{l}-0.4 \\
-0.1 \\
-0.5\end{array}$ & $\begin{array}{l}0.210 \\
0.496 \\
0.039\end{array}$ \\
\hline $\begin{array}{l}\text { Race/Ethnicity } \\
\text { White, non-Hispanic } \\
\text { Black, non-Hispanic } \\
\text { Asian, non-Hispanic } \\
\text { Native Hawaiian/Pacific Islander } \\
\text { American Indian/Alaska Native } \\
\text { Hispanic } \\
\text { Other }^{\S}\end{array}$ & $\begin{array}{l}29.0(28.7-29.3) \\
41.2(40.4-42.0) \\
25.4(23.9-27.0) \\
34.6(29.6-39.9) \\
36.2(34.0-38.4) \\
28.3(27.5-29.2) \\
27.7(25.5-30.0)\end{array}$ & $\begin{array}{l}29.3(29.0-29.5) \\
41.4(40.6-42.2) \\
27.0(25.2-28.8) \\
28.8(24.5-33.6) \\
34.2(32.2-36.3) \\
29.7(28.7-30.6) \\
29.2(26.7-31.7)\end{array}$ & $\begin{array}{l}28.8(28.5-29.0) \\
40.3(39.5-41.1) \\
24.6(22.9-26.3) \\
32.8(28.6-37.3) \\
35.0(33.1-37.1) \\
28.0(27.1-28.9) \\
28.0(25.5-30.8)\end{array}$ & $\begin{array}{r}-0.2 \\
-0.9 \\
-0.9 \\
-1.1 \\
-0.3 \\
0.3\end{array}$ & $\begin{array}{l}0.102 \\
0.094 \\
0.707 \\
0.523 \\
0.540 \\
0.789 \\
0.562\end{array}$ \\
\hline $\begin{array}{l}\text { Education } \\
\text { Less than high school } \\
\text { High school graduate } \\
\text { Some college } \\
\text { College graduate or higher }\end{array}$ & $\begin{array}{l}34.1(33.3-34.9) \\
32.2(31.7-32.6) \\
30.5(30.1-30.9) \\
25.2(24.8-25.5)\end{array}$ & $\begin{array}{l}36.2(35.3-37.1) \\
32.0(31.6-32.4) \\
31.0(30.5-31.4) \\
25.4(25.0-25.8)\end{array}$ & $\begin{array}{l}35.1(34.2-36.0) \\
31.9(31.4-32.3) \\
29.8(29.3-30.2) \\
24.9(24.5-25.3)\end{array}$ & $\begin{array}{r}1.0 \\
-0.3 \\
-0.7 \\
-0.3\end{array}$ & $\begin{array}{l}0.019 \\
0.574 \\
0.012 \\
0.136\end{array}$ \\
\hline
\end{tabular}

See table footnotes on next page.

and significant decreases were observed in six states (Michigan, Nevada, New Hampshire, New York, Texas, and Washington). In 2015, hypertension prevalence was, in general, higher in the Southern states and lower in the Western states (Figure).

Among participants with self-reported hypertension, the age-standardized prevalences of antihypertensive medication use in 2011,2013 , and 2015 were $63.0 \%, 62.0 \%$, and $61.8 \%$, respectively $(\mathrm{p}<0.001$, Table 2$)$. In 2015 , the prevalence of medication use was higher among women $(66.8 \%)$, adults aged $\geq 65$ years $(93.1 \%)$, and blacks $(60.7 \%)$, and lower among men $(58.5 \%)$, adults aged $18-44$ years $(41.2 \%)$, and Hispanics (55.4\%). From 2011 to 2015, significant decreases in antihypertensive medication use among persons with self-reported hypertension were observed among both men and women, persons aged $\geq 65$ years, whites, and high school graduates, as well as those with any college education. By state, a significant decrease in the prevalence of medication use was observed in Connecticut, Hawaii, North Carolina, South Carolina, Texas, Utah, and West Virginia. In 2015, the prevalence of medication use among persons with self-reported hypertension was highest in Louisiana (73.8\%) and lowest in Idaho (51.1\%). In general, the prevalence of medication use was higher in the Southern states and lower in the Western states (Figure).

Age-standardized estimates were lower than unadjusted estimates for self-reported hypertension (Supplementary Table 1; https://stacks.cdc.gov/view/cdc/50226) and substantially lower for antihypertension medication use (Supplementary Table 2; https://stacks.cdc.gov/view/cdc/50226). In addition, statistically significant increases were observed in the unadjusted prevalence of both hypertension (0.6\%), and antihypertension medication use from 2011 to 2015; however, the increase in medication use was small in magnitude $(0.1 \%)$.

\section{Discussion}

Among U.S. adults, the age-standardized prevalence of selfreported hypertension and antihypertension medication use changed little from 2011 to 2015. Differences were observed by age, sex, race/ethnicity, and state of residence.

A recent report using National Health and Nutrition Examination Survey data found no change in the prevalence of hypertension among U.S. adults, from 1999-2000 (28.4\%) to 2011-2012 (28.7\%) and 2015-2016 (29.0\%) (4). Because of the large number of participants in BRFSS each year, the statistically significant decline in hypertension prevalence from $30.1 \%$ to $29.8 \%$ likely does not represent a meaningful change. However, at the state level, both the age-standardized and unadjusted prevalences of hypertension declined significantly in Alaska, Michigan, Nevada, New Hampshire, and Texas and increased in Arkansas, Georgia, Hawaii, and West Virginia, which suggests that there might be notable changes in hypertension prevalence in these states.

The finding that the age-standardized prevalence of antihypertensive medication use declined slightly from 2011 (63.1\%) to 2015 (61.8\%) was unexpected, although the trend in unadjusted prevalence had no meaningful change (from $77.5 \%$ to $77.6 \%$ ). 
TABLE 1. (Continued) Age-standardized prevalence of self-reported hypertension among adults aged $\geq 18$ years by sociodemographic characteristics and state* - Behavioral Risk Factor Surveillance System, United States 2011-2015

\begin{tabular}{|c|c|c|c|c|c|}
\hline \multirow[b]{2}{*}{ Characteristic } & \multicolumn{3}{|c|}{$\%(95 \% \mathrm{Cl})$} & \multicolumn{2}{|c|}{ Change 2011-2015 } \\
\hline & 2011 & 2013 & 2015 & $\%$ & $p$-value ${ }^{\dagger}$ \\
\hline \multicolumn{6}{|l|}{ State } \\
\hline Alabama & $37.9(36.5-39.4)$ & $37.6(36.0-39.3)$ & $37.6(36.2-39.0)$ & -0.4 & 0.663 \\
\hline Alaska & $30.8(28.8-32.9)$ & $30.2(28.5-32.0)$ & $27.9(26.0-29.9)$ & -2.9 & 0.030 \\
\hline Arizona & $26.3(24.6-28.2)$ & $29.5(27.2-32.0)$ & $28.5(27.2-29.9)$ & 2.2 & 0.053 \\
\hline Arkansas & $33.7(31.9-35.6)$ & $36.4(34.5-38.3)$ & $36.7(34.5-39.0)$ & 3.1 & 0.033 \\
\hline California & $27.8(27.0-28.6)$ & $28.2(27.2-29.3)$ & $27.7(26.7-28.6)$ & -0.2 & 0.703 \\
\hline Colorado & $24.8(23.9-25.7)$ & $25.8(25.0-26.7)$ & $24.6(23.6-25.7)$ & -0.1 & 0.688 \\
\hline Connecticut & $27.6(26.3-29.0)$ & $28.3(27.0-29.6)$ & $27.0(26.0-28.1)$ & -0.6 & 0.518 \\
\hline Delaware & $32.5(30.8-34.3)$ & $32.6(31.0-34.2)$ & $31.2(29.4-33.2)$ & -1.3 & 0.262 \\
\hline District of Columbia & $31.0(29.3-32.8)$ & $30.2(28.6-32.0)$ & $31.0(28.7-33.4)$ & 0.0 & 0.927 \\
\hline Florida & $30.6(29.4-31.8)$ & $30.6(29.6-31.7)$ & $29.4(28.1-30.7)$ & -1.3 & 0.081 \\
\hline Georgia & $32.4(31.2-33.7)$ & $34.5(33.2-35.8)$ & $35.0(33.4-36.6)$ & 2.6 & 0.020 \\
\hline Hawaii & $26.8(25.5-28.2)$ & $26.2(24.9-27.5)$ & $29.7(28.3-31.2)$ & 2.9 & 0.013 \\
\hline Idaho & $28.9(27.3-30.5)$ & $27.7(26.2-29.2)$ & $29.6(28.0-31.3)$ & 0.8 & 0.528 \\
\hline Illinois & $30.1(28.5-31.7)$ & $28.7(27.2-30.3)$ & $28.9(27.6-30.2)$ & -1.1 & 0.333 \\
\hline Indiana & $31.3(30.1-32.5)$ & $31.6(30.5-32.7)$ & $30.0(28.5-31.6)$ & -1.3 & 0.228 \\
\hline lowa & $27.5(26.3-28.6)$ & $28.6(27.4-29.8)$ & $27.8(26.5-29.1)$ & 0.3 & 0.798 \\
\hline Kansas & $29.4(28.7-30.2)$ & $29.4(28.8-30.1)$ & $29.6(29.0-30.3)$ & 0.2 & 0.742 \\
\hline Kentucky & $36.1(34.7-37.5)$ & $36.6(35.4-37.9)$ & $36.3(34.8-37.9)$ & 0.2 & 0.726 \\
\hline Louisiana & $37.3(36.0-38.6)$ & $38.0(36.1-39.9)$ & $37.5(35.8-39.1)$ & 0.2 & 0.881 \\
\hline Maine & $28.6(27.6-29.5)$ & $29.2(27.9-30.4)$ & $29.0(27.7-30.2)$ & 0.4 & 0.431 \\
\hline Maryland & $29.9(28.7-31.2)$ & $30.9(29.8-32.0)$ & $30.6(29.1-32.1)$ & 0.7 & 0.356 \\
\hline Massachusetts & $27.6(26.7-28.5)$ & $27.1(26.1-28.1)$ & $27.2(26.0-28.3)$ & -0.4 & 0.695 \\
\hline Michigan & $32.1(30.9-33.3)$ & $31.8(30.7-32.8)$ & $30.0(29.0-31.1)$ & -2.0 & 0.008 \\
\hline Minnesota & $25.2(24.3-26.1)$ & $25.4(24.2-26.6)$ & $24.2(23.5-25.0)$ & -1.0 & 0.115 \\
\hline Mississippi & $37.8(36.6-39.1)$ & $38.3(36.8-39.8)$ & $40.1(38.4-41.8)$ & 2.2 & 0.063 \\
\hline Missouri & $32.3(30.8-33.8)$ & $29.5(27.9-31.1)$ & $31.5(30.1-33.0)$ & -0.7 & 0.356 \\
\hline Montana & $27.5(26.3-28.8)$ & $26.3(25.2-27.4)$ & $25.9(24.4-27.4)$ & -1.6 & 0.056 \\
\hline Nebraska & $26.9(26.3-27.6)$ & $28.4(27.5-29.5)$ & $27.7(26.8-28.7)$ & 0.8 & 0.227 \\
\hline Nevada & $30.6(28.6-32.7)$ & $29.4(27.5-31.5)$ & $26.7(24.5-29.0)$ & -3.9 & 0.009 \\
\hline New Hampshire & $28.7(27.3-30.2)$ & $27.1(25.8-28.5)$ & $25.8(24.4-27.2)$ & -2.9 & 0.005 \\
\hline New Jersey & $28.8(27.8-29.8)$ & $28.5(27.5-29.5)$ & $28.2(27.1-29.4)$ & -0.6 & 0.551 \\
\hline New Mexico & $27.0(26.0-28.1)$ & $27.4(26.3-28.6)$ & $28.0(26.6-29.4)$ & 0.9 & 0.341 \\
\hline New York & $29.1(27.9-30.5)$ & $29.4(28.2-30.6)$ & $27.2(26.2-28.2)$ & -1.9 & 0.018 \\
\hline North Carolina & $30.9(29.8-32.1)$ & $33.4(32.2-34.6)$ & $32.8(31.6-34.0)$ & 1.9 & 0.028 \\
\hline North Dakota & $27.4(26.1-28.8)$ & $27.6(26.4-28.8)$ & $28.9(27.5-30.3)$ & 1.5 & 0.100 \\
\hline Ohio & $30.4(29.2-31.6)$ & $30.5(29.4-31.6)$ & $31.2(29.9-32.5)$ & 0.8 & 0.417 \\
\hline Oklahoma & $33.9(32.7-35.2)$ & $35.6(34.4-36.9)$ & $33.9(32.5-35.3)$ & -0.1 & 0.895 \\
\hline Oregon & $27.8(26.5-29.2)$ & $29.5(28.0-31.1)$ & $27.5(26.1-28.9)$ & -0.3 & 0.721 \\
\hline Pennsylvania & $28.6(27.5-29.8)$ & $30.4(29.3-31.5)$ & $29.0(27.6-30.5)$ & 0.3 & 0.602 \\
\hline Rhode Island & $30.6(29.2-32.0)$ & $31.0(29.6-32.4)$ & $29.2(27.7-30.6)$ & -1.4 & 0.230 \\
\hline South Carolina & $34.1(32.9-35.3)$ & $35.5(34.3-36.7)$ & $34.7(33.6-35.9)$ & 0.6 & 0.489 \\
\hline South Dakota & $28.7(27.0-30.4)$ & $27.9(26.4-29.4)$ & $27.5(25.9-29.1)$ & -1.2 & 0.244 \\
\hline Tennessee & $37.0(34.6-39.4)$ & $36.2(34.6-37.9)$ & $35.3(33.6-36.9)$ & -1.7 & 0.360 \\
\hline Texas & $31.7(30.5-32.9)$ & $31.3(30.1-32.6)$ & $29.2(28.0-30.4)$ & -2.5 & 0.004 \\
\hline Utah & $25.0(24.2-25.9)$ & $25.7(24.8-26.5)$ & $25.0(24.1-25.8)$ & -0.1 & 0.891 \\
\hline Vermont & $26.7(25.5-28.0)$ & $27.7(26.4-29.0)$ & $25.7(24.5-27.0)$ & -1.0 & 0.299 \\
\hline Virginia & $30.0(28.6-31.5)$ & $30.9(29.7-32.2)$ & $31.5(30.3-32.8)$ & 1.5 & 0.193 \\
\hline Washington & $29.4(28.3-30.5)$ & $28.9(27.9-30.0)$ & $28.1(27.2-29.0)$ & -1.3 & 0.036 \\
\hline West Virginia & $33.8(32.4-35.3)$ & $36.8(35.4-38.3)$ & $38.6(37.1-40.0)$ & 4.8 & $<0.001$ \\
\hline Wisconsin & $27.0(25.3-28.7)$ & $29.7(28.1-31.4)$ & $26.8(25.4-28.3)$ & -0.2 & 0.918 \\
\hline Wyoming & $27.6(26.2-29.0)$ & $27.0(25.6-28.4)$ & $27.7(26.0-29.5)$ & 0.2 & 0.887 \\
\hline
\end{tabular}

Abbreviation: $\mathrm{Cl}=$ confidence interval.

* Directly standardized to the 2000 U.S. standard population.

† Adjusted for sex, age group, and race/ethnicity.

$\S$ Includes participants of multiple racial/ethnic groups.

A previous study found that hypertension medication prescriptions provided during U.S. physician office visits increased from $69.2 \%$ to $78.8 \%$ from $2003-2004$ to $2009-2010$ (5). U.S. prescription sales data also indicated that prescription fill counts for antihypertensive medication increased from 2009 to 2014 (6). Data from the National Health and Nutrition Examination 
FIGURE. Age-standardized prevalence of self-reported hypertension among adults (A) and use of antihypertensive medication among adults with self-reported hypertension (B), by state - Behavioral Risk Factor Surveillance System, 50 states and the District of Columbia (DC), 2015

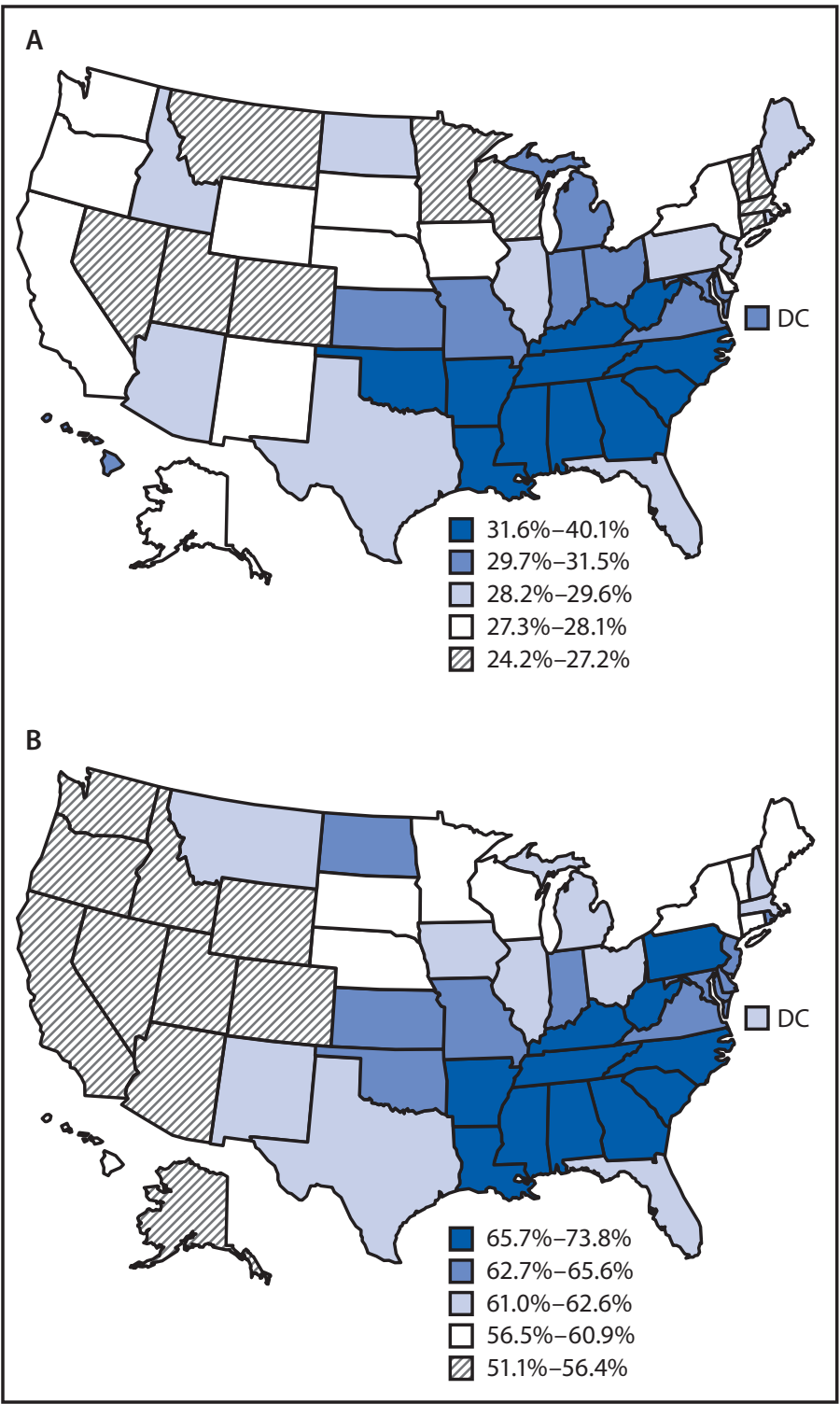

Survey indicated that antihypertensive medication use increased from $63.5 \%$ (2001-2002) to $77.3 \%$ (2009-2010) (7).

Reduction targets in the prevalence of hypertension and improvements in its management are included in many national initiatives. Healthy People 2020 heart disease and stroke objectives include reducing the proportion of persons in the population with hypertension (target $=26.9 \%$ ) and increasing the proportion of adults with hypertension who are taking the prescribed medications to lower their blood pressure (target $=69.5 \%)^{\S}$

\footnotetext{
\$https://www.healthypeople.gov/2020/topics-objectives/topic/ heart-disease-and-stroke.
}

\section{Summary}

What is already known about this topic?

Hypertension is a major risk factor for heart disease and stroke. Hypertension prevalence and treatment among the U.S. population varies by demographic characteristics and by state. What is added by this report?

During 2011-2015, overall, the age-standardized prevalence of hypertension (30.1\% in 2011 to $29.8 \%$ in 2015), as well as the use of antihypertensive medication among persons with self-reported hypertension (63.0\% in 2011 to 61.8\% in 2015), decreased slightly among U.S. adults. However, it is unclear whether these small changes are clinically meaningful.

What are the implications for public health practice?

Aggressive public health actions to expand existing, effective interventions could enhance improvement in hypertension prevention and management in order to achieve Healthy People 2020 goals.

Although improvements have been seen in hypertension management, Healthy People 2020 hypertension targets have yet to be realized. Whereas Healthy People 2020 objectives and targets are set for the United States, data from this report highlighting sociodemographic and geographic differences in the prevalence and treatment of hypertension can be used by state partners to target interventions to improve hypertension management within their populations and communities. Complementary to Healthy People 2020 and other programs, the U.S. Department of Health and Human Services Million Hearts initiative seeks to improve hypertension control through diverse, multifaceted interventions (8). CDC has been working with state and local public health communities to improve hypertension awareness, treatment, and control through multiple strategies within the CDC State Heart Disease and Stroke Prevention programs (9). In addition to effective, replicable interventions available through these programs, data from this report could be used by public health practitioners to inform hypertension awareness initiatives and management strategies with clinical partners.

The findings in this report are subject to at least three limitations. First, BRFSS data are based on self-report; the lack of direct blood pressure measurement makes it impossible to fully assess hypertension prevalence or control according to current guidelines. Based on data from the National Health and Nutrition Examination Survey, the prevalence of awareness among adults with hypertension was $83.3 \%$ during 2011-2014 (10). Therefore, nearly $20 \%$ of adults with hypertension are unaware of their condition. Second, the representativeness of the BRFSS sample might be affected by median response rates of $<50 \%$ across the states. Finally, because hypertension is related

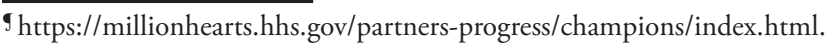


TABLE 2. Age-standardized prevalence of use of antihypertensive medication among adults aged $\geq 18$ years with self-reported hypertension, by sociodemographic characteristics and state* - Behavioral Risk Factor Surveillance System, United States, 2011-2015

\begin{tabular}{|c|c|c|c|c|c|}
\hline \multirow[b]{2}{*}{ Characteristic } & \multicolumn{3}{|c|}{$\%(95 \% \mathrm{Cl})$} & \multicolumn{2}{|c|}{ Change 2011-2015 } \\
\hline & 2011 & 2013 & 2015 & $\%$ & p-value ${ }^{\dagger}$ \\
\hline Total & $63.0(62.3-63.8)$ & $62.0(61.3-62.7)$ & $61.8(61.0-62.5)$ & -1.3 & $<0.001$ \\
\hline \multicolumn{6}{|l|}{ Sex } \\
\hline Male & $59.6(58.7-60.6)$ & $58.3(57.4-59.2)$ & $58.5(57.6-59.4)$ & -1.1 & 0.029 \\
\hline Female & $68.2(67.1-69.2)$ & $67.1(66.0-68.2)$ & $66.8(65.7-67.9)$ & -1.3 & 0.007 \\
\hline \multicolumn{6}{|l|}{ Age group (yrs) } \\
\hline $18-44$ & $42.9(41.6-44.2)$ & $41.4(40.1-42.6)$ & $41.2(39.9-42.5)$ & -1.7 & 0.180 \\
\hline $45-64$ & $81.2(80.6-81.8)$ & 80.7 (80.1-81.3) & 80.3 (79.7-80.9) & -0.9 & 0.048 \\
\hline$\geq 65$ & $93.9(93.6-94.2)$ & 93.1 (92.8-93.4) & 93.1 (92.8-93.4) & -0.8 & $<0.001$ \\
\hline \multicolumn{6}{|l|}{ Race/Ethnicity } \\
\hline White, non-Hispanic & $63.1(62.3-64.0)$ & $61.9(61.1-62.7)$ & 60.7 (59.8-61.5) & -2.5 & $<0.001$ \\
\hline Black, non-Hispanic & 69.7 (67.8-71.4) & 68.7 (67.0-70.4) & 70.7 (68.8-72.4) & 1.0 & 0.146 \\
\hline Asian, non-Hispanic & $59.9(55.6-64.0)$ & $58.2(53.3-62.8)$ & 62.7 (58.6-66.6) & 2.8 & 0.491 \\
\hline Native Hawaiian/Pacific Islander & $63.8(53.4-73.0)$ & $56.3(47.3-65.0)$ & $55.1(46.4-63.5)$ & -8.7 & 0.148 \\
\hline American Indian/Alaska Native & $61.8(57.5-66.0)$ & $62.0(57.8-66.0)$ & $61.2(56.5-65.6)$ & -0.7 & 0.867 \\
\hline Hispanic & $54.6(52.5-56.8)$ & $55.4(53.3-57.5)$ & $55.4(53.3-57.5)$ & 0.8 & 0.952 \\
\hline Other ${ }^{\S}$ & $61.2(54.2-67.7)$ & $57.4(50.6-64.0)$ & $60.6(53.1-67.7)$ & -0.5 & 0.771 \\
\hline \multicolumn{6}{|l|}{ Education } \\
\hline Less than high school & $60.0(58.0-62.0)$ & $59.8(57.7-61.8)$ & $60.3(58.0-62.5)$ & 0.3 & 0.845 \\
\hline High school graduate & $64.3(63.0-65.6)$ & $62.7(61.4-63.9)$ & $61.8(60.5-63.1)$ & -2.4 & 0.031 \\
\hline Some college & $62.6(61.4-63.9)$ & $61.5(60.2-62.7)$ & $61.8(60.5-63.0)$ & -0.8 & 0.128 \\
\hline College graduate or higher & $64.1(62.8-65.4)$ & $63.4(62.2-64.6)$ & $62.5(61.2-63.7)$ & -1.6 & 0.002 \\
\hline
\end{tabular}

See table footnotes on next page.

to age, the slight decline in the age-standardized prevalence of medication use during the analysis period could be caused by the mathematical distortion of standardizing to a general population age distribution, or could reflect reporting bias.

This report provides the most current self-reported state-level hypertension surveillance data. Hypertension remains a significant public health problem. Public health and health system interventions might help to improve hypertension awareness and management. A substantial evidence base is available to inform programs at multiple levels and across diverse settings to support improvements in hypertension management.*, ${ }^{* \dagger}$

\footnotetext{
** https://www.thecommunityguide.org/topic/cardiovascular-disease.

$\dagger$ https://millionhearts.hhs.gov/files/HTN_Change_Package.pdf.
}

\section{Conflict of Interest}

No conflicts of interest were reported.

\footnotetext{
${ }^{1}$ Division for Heart Disease and Stroke Prevention, National Center for Chronic Disease Prevention and Health Promotion, CDC.

Corresponding author: Jing Fang, jfang@cdc.gov.
}

\section{References}

1. Benjamin EJ, Blaha MJ, Chiuve SE, et al.; American Heart Association Statistics Committee and Stroke Statistics Subcommittee. Heart disease and stroke statistics - 2017 update: a report from the American Heart Association. Circulation 2017;135:e146-603. https://doi.org/10.1161/ CIR.0000000000000485
2. Chobanian AV, Bakris GL, Black HR, et al.; Joint National Committee on Prevention, Detection, Evaluation, and Treatment of High Blood Pressure. National Heart, Lung, and Blood Institute; National High Blood Pressure Education Program Coordinating Committee. Seventh report of the Joint National Committee on Prevention, Detection, Evaluation, and Treatment of High Blood Pressure. Hypertension 2003;42:1206-52. https://doi.org/10.1161/01.HYP.0000107251.49515.c2

3. CDC. Self-reported hypertension and use of antihypertensive medication among adults-United States, 2005-2009. MMWR Morb Mortal Wkly Rep 2013;62:237-44.

4. Fryar CD, Ostchega Y, Hales CM, Zhang G, Kruszon-Moran D. Hypertension prevalence and control among adults: United States, 2015-2016. NCHS data brief, no 289. Hyattsville, MD: US Department of Health and Human Services, CDC, National Center for Health Statistics; 2017.

5. GuA, YueY, Argulian E. Age differences in treatment and control of hypertension in US physician offices, 2003-2010: a serial cross-sectional study. Am J Med 2016;129:50-58.e4. https://doi.org/10.1016/j.amjmed.2015.07.031

6. Ritchey M, Tsipas S, Loustalot F, Wozniak G. Use of pharmacy sales data to assess changes in prescription- and payment-related factors that promote adherence to medications commonly used to treat hypertension, 2009 and 2014. PLoS One 2016;11:e0159366. https://doi.org/10.1371/journal.pone.0159366

7. Gu Q, Burt VL, Dillon CF, Yoon S. Trends in antihypertensive medication use and blood pressure control among United States adults with hypertension: the National Health And Nutrition Examination Survey, 2001 to 2010. Circulation 2012;126:2105-14. https://doi. org/10.1161/CIRCULATIONAHA.112.096156

8. CDC. Million hearts: strategies to reduce the prevalence of leading cardiovascular disease risk factors-United States, 2011. MMWR Morb Mortal Wkly Rep 2011;60:1248-51.

9. CDC. CDC state heart disease and stroke prevention programs. Atlanta, GA: US Department of Health and Human Services, CDC; 2017. https://www.cdc.gov/dhdsp/programs/index.htm

10. Yoon SS, Gu Q, Nwankwo T, Wright JD, Hong Y, Burt V. Trends in blood pressure among adults with hypertension: United States, 2003 to 2012. Hypertension 2015;65:54-61. https://doi.org/10.1161/ HYPERTENSIONAHA.114.04012 
TABLE 2. (Continued) Age-standardized prevalence of use of antihypertensive medication among adults aged $\geq 18$ years with self-reported hypertension, by sociodemographic characteristics and state* — Behavioral Risk Factor Surveillance System, United States, 2011-2015

\begin{tabular}{|c|c|c|c|c|c|}
\hline \multirow[b]{2}{*}{ Characteristic } & \multicolumn{3}{|c|}{$\%(95 \% \mathrm{Cl})$} & \multicolumn{2}{|c|}{ Change 2011-2015 } \\
\hline & 2011 & 2013 & 2015 & $\%$ & $p$-value ${ }^{\dagger}$ \\
\hline \multicolumn{6}{|l|}{ State } \\
\hline Alabama & $72.7(69.3-75.9)$ & $71.2(67.0-75.0)$ & $70.4(66.9-73.6)$ & -2.4 & 0.392 \\
\hline Alaska & $52.3(47.8-56.7)$ & $48.6(44.5-52.7)$ & $51.7(46.3-57.1)$ & -0.5 & 0.455 \\
\hline Arizona & $56.3(50.6-61.8)$ & $50.8(45.6-55.9)$ & $56.1(52.2-60.0)$ & -0.1 & 0.701 \\
\hline Arkansas & $67.6(62.0-72.9)$ & $66.5(61.9-70.8)$ & $66.5(60.7-71.8)$ & -1.2 & 0.958 \\
\hline California & $53.8(51.5-56.2)$ & $54.0(51.1-56.8)$ & $53.3(50.8-55.8)$ & -0.5 & 0.286 \\
\hline Colorado & $51.6(48.6-54.5)$ & $54.6(51.9-57.4)$ & $54.0(50.6-57.4)$ & 2.4 & 0.916 \\
\hline Connecticut & $63.2(58.9-67.3)$ & $58.3(54.1-62.3)$ & $58.1(54.2-61.9)$ & -5.1 & 0.001 \\
\hline Delaware & $63.9(59.2-68.3)$ & $70.1(65.2-74.6)$ & $63.5(57.6-69.0)$ & -0.4 & 0.717 \\
\hline District of Columbia & $64.2(58.5-69.5)$ & $59.7(54.7-64.4)$ & $61.0(54.4-67.2)$ & -3.2 & 0.588 \\
\hline Florida & $61.9(58.3-65.3)$ & $60.8(57.8-63.8)$ & $62.6(58.6-66.3)$ & 0.7 & 0.665 \\
\hline Georgia & $68.5(64.8-72.0)$ & $66.8(63.5-70.0)$ & $65.7(61.3-69.9)$ & -2.8 & 0.890 \\
\hline Hawaii & $65.6(60.9-70.1)$ & $62.8(58.3-67.2)$ & $58.9(54.9-62.7)$ & -6.7 & 0.002 \\
\hline Idaho & $52.6(48.6-56.6)$ & $54.6(49.7-59.5)$ & $51.1(46.9-55.2)$ & -1.5 & 0.159 \\
\hline Illinois & $62.5(57.6-67.2)$ & $60.7(55.8-65.4)$ & $62.0(57.6-66.2)$ & -0.6 & 0.690 \\
\hline Indiana & $65.4(61.8-68.8)$ & $64.9(61.6-68.0)$ & $63.1(58.1-67.8)$ & -2.3 & 0.339 \\
\hline lowa & $58.7(55.2-62.1)$ & $61.2(57.3-65.0)$ & $61.4(57.0-65.7)$ & 2.7 & 0.395 \\
\hline Kansas & $62.1(59.9-64.2)$ & $62.7(60.6-64.7)$ & $62.6(60.6-64.6)$ & 0.5 & 0.655 \\
\hline Kentucky & $67.6(64.2-70.8)$ & $69.2(66.1-72.2)$ & $68.2(64.2-71.9)$ & 0.6 & 0.471 \\
\hline Louisiana & 73.9 (70.7-76.9) & $70.4(65.8-74.7)$ & $73.8(69.7-77.6)$ & -0.1 & 0.828 \\
\hline Maine & $61.1(57.9-64.2)$ & $64.7(60.7-68.5)$ & $57.1(53.2-60.9)$ & -4.0 & 0.094 \\
\hline Maryland & $68.8(64.9-72.4)$ & $66.0(62.6-69.3)$ & $63.4(58.7-67.8)$ & -5.4 & 0.054 \\
\hline Massachusetts & $61.1(58.2-63.9)$ & $56.5(53.3-59.6)$ & $62.1(58.4-65.6)$ & 0.9 & 0.784 \\
\hline Michigan & $62.1(58.8-65.3)$ & $58.0(55.0-60.9)$ & $61.5(58.3-64.5)$ & -0.7 & 0.908 \\
\hline Minnesota & $60.9(57.6-64.0)$ & $59.9(56.2-63.6)$ & $60.7(57.8-63.4)$ & -0.2 & 0.851 \\
\hline Mississippi & 71.9 (68.9-74.7) & $73.7(70.1-77.1)$ & $72.1(68.0-75.9)$ & 0.2 & 0.838 \\
\hline Missouri & $64.8(60.6-68.8)$ & $72.7(67.3-77.5)$ & $65.6(61.3-69.7)$ & 0.8 & 0.607 \\
\hline Montana & $55.2(51.4-58.9)$ & $56.3(52.9-59.5)$ & $61.8(56.2-67.0)$ & 6.6 & 0.118 \\
\hline Nebraska & 60.7 (58.3-62.9) & $64.0(60.6-67.2)$ & $60.2(56.9-63.4)$ & -0.5 & 0.685 \\
\hline Nevada & $54.8(49.4-60.0)$ & $59.9(53.9-65.6)$ & $52.1(45.8-58.4)$ & -2.7 & 0.363 \\
\hline New Hampshire & $56.6(52.7-60.5)$ & $56.7(52.6-60.6)$ & $60.2(54.7-65.5)$ & 3.6 & 0.398 \\
\hline New Jersey & $60.1(57.1-63.0)$ & $59.3(56.3-62.2)$ & $64.0(60.0-67.7)$ & 3.9 & 0.506 \\
\hline New Mexico & $60.9(57.1-64.6)$ & $57.3(53.7-60.7)$ & $61.6(56.7-66.2)$ & 0.7 & 0.315 \\
\hline New York & $61.6(57.4-65.7)$ & $59.8(56.2-63.3)$ & $60.9(57.3-64.3)$ & -0.7 & 0.080 \\
\hline North Carolina & $74.0(70.3-77.3)$ & $63.1(59.9-66.2)$ & $68.2(64.5-71.6)$ & -5.8 & 0.007 \\
\hline North Dakota & $61.4(56.9-65.8)$ & $64.1(59.9-68.1)$ & $65.2(60.3-69.8)$ & 3.8 & 0.069 \\
\hline Ohio & $65.9(62.2-69.4)$ & $64.5(61.2-67.6)$ & $62.4(58.7-66.0)$ & -3.5 & 0.686 \\
\hline Oklahoma & $68.6(65.2-71.7)$ & $68.9(65.7-71.8)$ & $64.8(60.7-68.8)$ & -3.7 & 0.054 \\
\hline Oregon & $54.9(51.0-58.7)$ & $56.1(51.5-60.6)$ & $54.1(49.8-58.3)$ & -0.8 & 0.545 \\
\hline Pennsylvania & $62.9(59.4-66.2)$ & $64.2(61.2-67.2)$ & $65.8(61.2-70.2)$ & 3.0 & 0.164 \\
\hline Rhode Island & $62.1(57.9-66.2)$ & $64.4(60.2-68.4)$ & $63.3(57.9-68.3)$ & 1.2 & 0.642 \\
\hline South Carolina & $72.3(69.1-75.3)$ & $68.8(65.7-71.8)$ & $67.5(64.3-70.6)$ & -4.8 & 0.020 \\
\hline South Dakota & $60.2(54.9-65.3)$ & $64.0(59.1-68.6)$ & $59.3(54.5-64.0)$ & -0.9 & 0.740 \\
\hline Tennessee & $66.7(60.7-72.1)$ & $73.6(69.3-77.4)$ & $67.6(63.0-71.9)$ & 0.9 & 0.745 \\
\hline Texas & 65.5 (61.9-68.9) & $63.8(60.2-67.3)$ & $61.7(58.0-65.3)$ & -3.8 & 0.042 \\
\hline Utah & 56.7 (53.8-59.5) & $54.1(51.6-56.5)$ & $52.5(49.9-55.1)$ & -4.2 & 0.039 \\
\hline Vermont & $57.8(53.5-62.0)$ & $53.3(49.2-57.4)$ & $57.8(53.4-62.2)$ & 0.0 & 0.508 \\
\hline Virginia & $67.5(62.8-71.9)$ & $65.7(62.3-69.0)$ & $62.9(59.7-66.0)$ & -4.6 & 0.248 \\
\hline Washington & 54.7 (51.4-57.9) & $53.0(50.1-55.9)$ & $53.4(50.6-56.1)$ & -1.3 & 0.219 \\
\hline West Virginia & 73.8 (70.1-77.3) & $68.1(64.7-71.3)$ & $67.2(64.0-70.3)$ & -6.6 & $<0.001$ \\
\hline Wisconsin & $61.7(55.7-67.3)$ & $61.0(55.8-66.0)$ & $58.4(53.4-63.2)$ & -3.3 & 0.070 \\
\hline Wyoming & $57.3(53.0-61.4)$ & $57.8(53.0-62.4)$ & $56.4(50.8-61.8)$ & -0.9 & 0.858 \\
\hline
\end{tabular}

Abbreviation: $\mathrm{Cl}=$ confidence interval.

* Directly standardized to the 2000 U.S. standard population.

† Adjusted for sex, age group, and race/ethnicity.

$\S$ Includes participants of multiple racial/ethnic groups. 